\title{
Analysis of polymorphisms in milk proteins from cloned and sexually reproduced goats
}

\author{
H. Xing ${ }^{1,2}$, B. Shao ${ }^{1}$, Y.Y. Gu ${ }^{1}$, Y.G. Yuan ${ }^{1,2}$, T. Zhang ${ }^{1}$, J. Zang ${ }^{1}$ and Y. Cheng ${ }^{1,2}$ \\ ${ }^{1}$ College of Veterinary Medicine, Yangzhou University, Yangzhou, China \\ 2Jiangsu Co-Innovation Center for Prevention and Control of Important Animal \\ Infectious Diseases and Zoonoses, Yangzhou, China \\ Corresponding author: Y. Cheng \\ E-mail: chengyong@yzu.edu.cn
}

Genet. Mol. Res. 14 (4): 16196-16203 (2015)

Received July 22, 2015

Accepted September 2, 2015

Published December 8, 2015

DOI http://dx.doi.org/10.4238/2015.December.8.9

ABSTRACT. This study evaluates the relationship between the genotype and milk protein components in goats. Milk samples were collected from cloned goats and normal white goats during different postpartum (or abortion) phases. Two cloned goats, originated from the same somatic line of goat mammary gland epithelial cells, and three sexually reproduced normal white goats with no genetic relationships were used as the control. The goats were phylogenetically analyzed by polymerase chain reaction-restriction fragment length polymorphism. The milk protein components were identified by sodium dodecyl sulfate polyacrylamide gel electrophoresis. The results indicated that despite the genetic fingerprints being identical, the milk protein composition differed between the two cloned goats. The casein content of cloned goat C-50 was significantly higher than that of cloned goat C-4. Conversely, although the genetic fingerprints of the normal white goats $\mathrm{N}-1, \mathrm{~N}-2$, and $\mathrm{N}-3$ were not identical, the milk protein profiles did not differ significantly in their milk samples (obtained on postpartum day $15,20,25,30$, and 150). These results indicated an association between milk protein phenotypes and genetic polymorphisms, epigenetic regulation, and/or non-chromosomal factors. This study extends 
the knowledge of goat milk protein polymorphisms, and provides new strategies for the breeding of high milk-yielding goats.

Key words: Goat; Genotype; Milk protein; Polymorphism; SDS-PAGE

\section{INTRODUCTION}

The identification of superior animal populations with desirable characteristics and a higher production performance is essential in modern livestock breeding technology. Polymorphisms in milk proteins are important genetic markers for analyzing genetic variations in dairy animals; these may be used to identify goats with high milk yield, which may exert a significant economic impact. Polymorphisms in milk proteins have been previously determined via electrophoresis, whereas the correlations between protein polymorphisms and the biological characteristics of the animals can be determined using genetic markers; these, in turn, provide information regarding the economic traits and techniques of animal breeding (Amigo et al., 2000; Zulloa et al., 2005).

Polymorphisms in milk proteins have been investigated since 1995. Aschaffenburg and Drewry (1995) identified a polymorphism in $\beta$-lactoglobulin of Holstein milk by starch-gel electrophoresis. Subsequent analyses have also detected polymorphisms in five major protein fractions of cow milk: as-1-casein, as-2-casein, $\beta$-casein, k-casein, and $\alpha$-lactalbumin (Lagonigro et al., 2001; Marletta et al., 2004; Sacchi et al., 2005; Lan et al., 2007; Caravaca et al., 2009). Furthermore, milk protein polymorphisms have been associated with various characteristics of dairy cattle, such as production and quality of milk, reproduction, and resistance to disease (Luo et al., 1994; Ikonen et al., 1999; Zulloa et al., 2005; Pazzola et al., 2014). Very few studies in China have focused on the identification and characterization of milk protein polymorphisms; in fact, studies on polymorphisms in cloned goat milk proteins have not been reported in China. Therefore, the main aim of this study was to analyze polymorphisms in goat milk protein by sodium dodecyl sulfate polyacrylamide gel electrophoresis (SDS-PAGE), compare the milk protein composition between cloned goats and normal white goats, explore and track the genetic inheritance of cloned goats, and to provide a theoretical basis for future breeding and expansion of the technology of transgenic cloned goats.

\section{MATERIAL AND METHODS}

\section{Equipment}

The following equipment and instrumentation were employed in this study: horizontal flat plate/vertical slab electrophoresis apparatus (POWER-PAC300; Bio-Rad, Hercules, CA< USA); gel image analysis system (GIS-1000; Tanon Science \& Technology Co., Ltd., Shanghai, China); HB-PX-MAN thermal cycler (Hybaid, Chesire, UK); GTL-16A centrifuge (Nanda Biotechnology Co., Jiangsu, China); and a graduated pipette, conical flask, and transferpettor.

\section{Animals}

Two goats cloned from a somatic cell (C-50 and C-4) were created by the Veterinary College of Yangzhou University. The nuclear donor cells were obtained from a GMEC7\# cell line derived from the same mammary epithelial cells. Three normal white goats $(\mathrm{N}-1, \mathrm{~N}-2$, and $\mathrm{N}-3)$ from the Yangzhou area of China were used as controls. The goats were kept at the Research Farm 
at Yangzhou University (Yangzhou, Jiangsu, China); they were fed with alfalfa hay and given free access to salt, mineral mixtures, and water. The cloned goat C-4 had an accidental abortion 120 days after mating, while the other goats had normal parturition after pregnancies lasting 148-154 days. All procedures were performed in accordance with the Guiding Principles for the Care and Use of Laboratory Animals, and were approved by the Institutional Animal Care and Use Committee of Yangzhou University.

\section{Reagents and sample preparation}

All reagents used in this study were of analytical grade except when otherwise stated. Cell lysates (100 mL) were prepared using $10 \mathrm{~mL} 1 \mathrm{M}$ Tris- $\mathrm{HCl}$ (pH 8.5), $2 \mathrm{~mL} 200 \mathrm{mM}$ EDTA, $1 \mathrm{~mL} 20 \%$ SDS, $4 \mathrm{~mL} 5 \mathrm{M} \mathrm{NaCl}$, and $83 \mathrm{~mL}$ deionized distilled water $\left(\mathrm{ddH}_{2} \mathrm{O}\right)$. PCR primers were designed for the second exon of the goat major histocompatibility complex (MHC) II DRB gene (DRB1.1, 5'-TAT CCC GTC TCT GCA GCA CAT TTC-3'; Gio, 5'-CGT ACC CAG AGT GAG TGA AGT ATC-3'; and DRB1.2, 5'-TCG CCG CTG CAC ACT GAA ACT CTC-3'). The PCR primers were synthesized by Shanghai Boya Biotechnology Co. (Shanghai, China).

Protein electrophoresis was performed by SDS-PAGE. Gel solutions were formulated with $30 \%$ acrylamide/N,N'-methylenebis (acrylamide) [29\% acrylamide (w/v) + 1\% N,N'-methylenebis (acrylamide) (w/v)] and 10\% (w/v) sodium dodecyl sulfate (SDS). Separating gel (12\%) and concentrating gel (5\%) was separately prepared with N,N,N',N-tetramethylethylenediamine (TEMED), using $10 \%$ ammonium persulfate as the catalyst. The 2X SDS loading buffer contained $100 \mathrm{mM}$ Tris- $\mathrm{HCl}$ (pH 6.8), 200 mM dithiothreitol (DTT), 10\% mercaptoethanol, 4\% SDS, 0.2\% bromophenol blue, and $20 \%$ glycerol. The $5 X$ electrophoresis buffer contained $3.0 \mathrm{~mol} / \mathrm{L}$ Tris (pH 8.8), 10\% glycine, and $10 \%$ SDS. The staining solution contained $0.25 \mathrm{~g}$ Coomassie Blue R250 in $90 \mathrm{~mL} 1: 1$ methanol: water $+10 \mathrm{~mL}$ acetic acid, which was filtered with Whatman (no. 1) paper and stored at $4^{\circ} \mathrm{C}$. The de-staining solution contained $30 \%$ methanol, $10 \%$ acetic acid, and $60 \%$ hydrogen peroxide.

\section{Polymerase chain reaction restriction fragment length polymorphism (PCR-RFLP) analysis of cloned goats and normal white goats}

The genetic similarities between experimental goats were determined by PCR-RFLP. Morphological similarities were determined by analyzing the phenotypes, such as coat color, coat pattern, and gender. Genomic DNA extracted from goat ear tissues were used as the template for PCR amplification. The PCR protocol was as follows: initial denaturation at $94^{\circ} \mathrm{C}$ for 5 min using the primers DRB1.1 and Gio; addition of Taq polymerase (hot start), followed by 10 cycles of denaturation at $94^{\circ} \mathrm{C}$ for $1 \mathrm{~min}$, annealing at $60^{\circ} \mathrm{C}$ for $2 \mathrm{~min}$, and extension at $72^{\circ} \mathrm{C}$ for 2 min; addition of primers DRB1.1 (10 $\mu \mathrm{M}, 1.5 \mu \mathrm{L})$ and DRB1.2 $(10 \mu \mathrm{M}, 1.5 \mu \mathrm{L})$; and 30 cycles of denaturation at $94^{\circ} \mathrm{C}$ for $1 \mathrm{~min}$, annealing at $65^{\circ} \mathrm{C}$ for $30 \mathrm{~s}$, and extension at $72^{\circ} \mathrm{C}$ for $30 \mathrm{~s}$. The PCR products were digested with Rsal, and the digested products were analyzed by electrophoresing on $15 \%$ polyacrylamide gels. The obtained bands were analyzed using an imaging system.

\section{Collection and processing of goat milk samples}

Goat milk samples were collected regularly and stored at $-20^{\circ} \mathrm{C}$. The milk samples were processed as follows: goat skim milk was prepared by centrifuging whole milk at $8000 \mathrm{~g}$ for $20 \mathrm{~min}$ 
at $4^{\circ} \mathrm{C}$, and removing the upper cream layer. Skim milk was adjusted to $\mathrm{pH} 4.6$ with $1.0 \mathrm{~mol} / \mathrm{L} \mathrm{HCl}$, and centrifuged at $10,000 \mathrm{~g}$ for $30 \mathrm{~min}$ at $4^{\circ} \mathrm{C}$. The supernatant was analyzed by SDS-PAGE.

\section{SDS-PAGE of processed milk samples}

Skim milk proteins were detected by SDS-PAGE (Laemmli, 1970). The samples were electrophoresed under reducing conditions with mercaptoethanol, and stained with Coomassie Brilliant Blue R250. The stained protein bands were scanned and analyzed using the gel imaging system. Polymorphisms in whey and casein proteins were analyzed using the method reported by Medrano and Sharrow (1989). The protein type was determined by comparing against reference values for casein or skimmed milk in cattle and goats (Ambrosoli et al., 1988; Medrano and Sharrow, 1989).

\section{RESULTS}

\section{Phenotypic identification of normal white goats and cloned goats}

The phenotypes (age, gender, coat color, and horn) of cloned goats and normal white goats are summarized in Table 1. The phenotypes of the two cloned goats (GMEC7\# cell line) were identical. The only phenotype that was identical among the normal white control goats was their coat color; the goats differed in all other phenotypes. The two cloned goats were derived from the same cell line with the same genetic background; therefore, they displayed the same phenotype. The three white goat controls exhibited different phenotypes because of the differences in parent genotypes.

Table 1. Phenotypes of normal white goats (control) and cloned goats.

\begin{tabular}{|c|c|c|c|c|c|}
\hline Individual designation & Gender & Cell line & Coat color & Horn & Age (years) \\
\hline C-50 & q & GMEC $7^{\#}$ & Dark fleck, white base & No horn & 3 \\
\hline C-4 & 우 & GMEC $7^{\#}$ & Dark fleck, white base & No horn & 3 \\
\hline $\mathrm{N}-1$ & 우 & & White & Horned & 3.3 \\
\hline $\mathrm{N}-2$ & o & & White & No horn & 3.5 \\
\hline $\mathrm{N}-3$ & o & & White & Horned & 2.5 \\
\hline
\end{tabular}

\section{Genotypic identification of normal white goats and cloned goats}

The goat genotypes were identified by PCR-RFLP. The two cloned goats had the same band pattern, which was identical to that of the donor goat (Figure 1). The band patterns of the three normal control goats differed from each other, and from those of the cloned goats (Figure 1). Therefore, the two cloned goats shared the same genotype, while the normal control goats expressed genotypes that differed from each other and from those of the cloned goats.

\section{Milk protein composition in cloned and control goats}

Skimmed milk was subjected to SDS-PAGE analysis under reducing conditions and stained with Coomassie blue (Figures 2-4). All samples contained $\alpha$-lactalbumin ( $\alpha$-La), $\beta$-lactoglobulin ( $\beta$ $\mathrm{Lg}$ ), casein $(\mathrm{CN})$, and serum albumin $(\mathrm{SA})$. The relative content of the major milk proteins were quantified by imaging the gel, and analyzing it with appropriate software. $\beta$-lactoglobulin constituted the highest percentage of proteins in the milk produced by all experimental goats, followed by $a$-lactalbumin and casein. In this study, the highest casein content the maximum number of 
casein isoforms were present in milk produced by the cloned goat C-50 during each postpartum period (Figures 2 and 3). The proteins in milk obtained from the three normal control goats during postnatal days $15,20,25,30$, and 150 did not differ significantly.

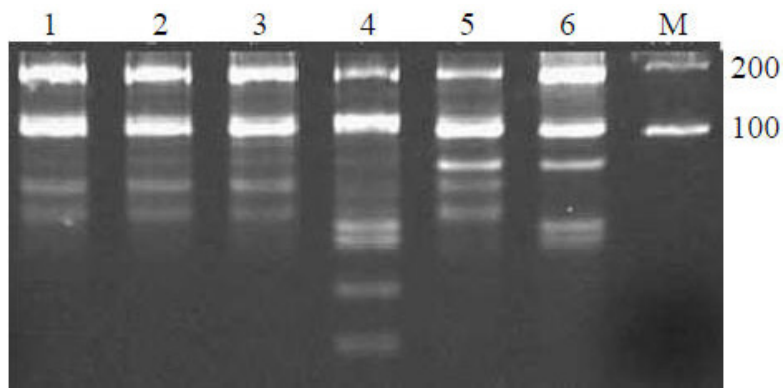

Figure 1. Genetic identification of goats by polymerase chain reaction restriction fragment length polymorphism (PCRRFLP). Lane 1, cloned goat C-50; Lane 2, cloned goat C-4; Lane 3, donor goat for somatic cloning; Lane 4, normal white goat N-1; Lane 5, normal white goat N-2; Lane 6, normal white goat N-3; Lane M, DNA marker (kB).

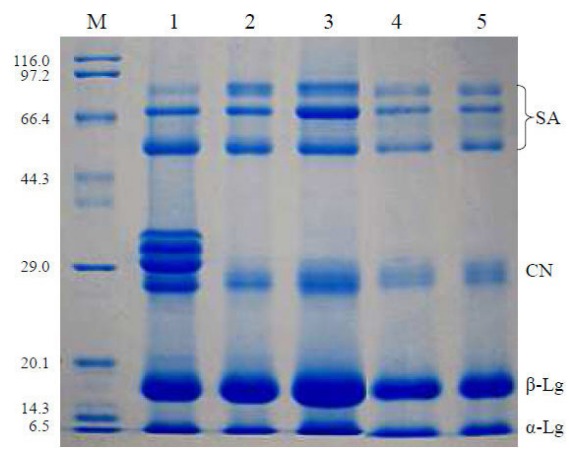

Figure 2. Sodium dodecyl sulfate polyacrylamide gel electrophoresis (SDS-PAGE) of proteins in goat milk sampled on the first postpartum day or first day after abortion. Lane M, protein marker (kD); Lane 1, C-50; Lane 2, C-4; Lane 3, $\mathrm{N}-1$; Lane 4, N-2; Lane 5, N-3. All samples contained $50 \mathrm{mg}$ protein in $5 \mathrm{~mL}$ loading buffer.

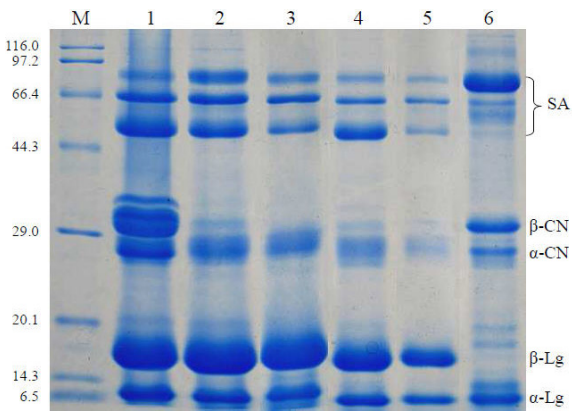

Figure 3. SDS-PAGE patterns of milk protein from goats with different genetic backgrounds. Lane $M$, protein marker (kDa); Lane 1, C-50 (second day postpartum); Lane 2, C-4 (second day after abortion); Lane 3, N-1 (second day postpartum); Lane 4, N-2 (second day postpartum); Lane 5, N-3 (second day postpartum); Lane 6, human milk. All samples contained $50 \mathrm{mg}$ protein in $5 \mathrm{~mL}$ loading buffer. 


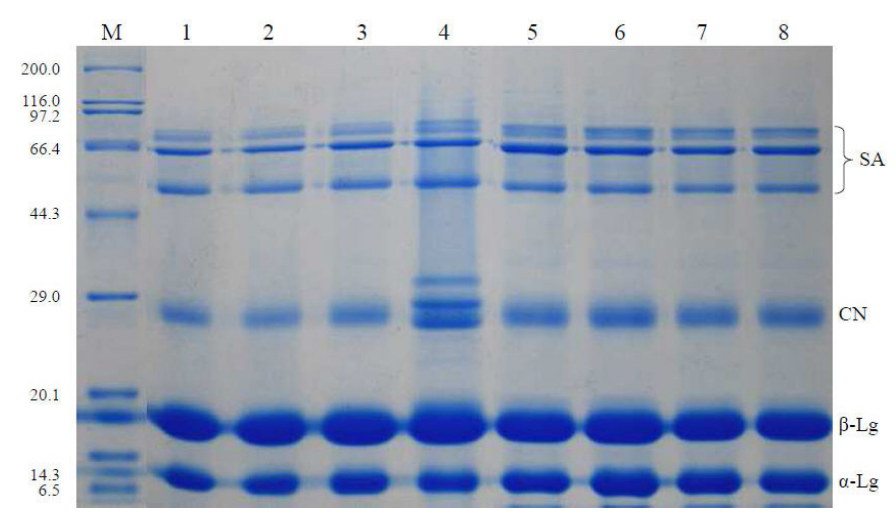

Figure 4. SDS-PAGE of goat milk proteins sampled 15-30 days postpartum. Lane $M$, protein marker (kDa); Lane 1, C-50 (15 days postpartum); Lane 2, C-50 (20 days postpartum); Lane 3, C-50 (25 days postpartum); Lane 4, C-50 (30 days postpartum); Lane 5, N-2 (15 days postpartum); Lane 6, N-2 (20 days postpartum); Lane 7, N-2 (25 days postpartum); Lane $8, \mathrm{~N}-2$ (30 days postpartum). All samples contained $50 \mathrm{mg}$ protein in $5 \mathrm{~mL}$ loading buffer.

\section{Milk protein polymorphisms}

The SDS-PAGE gels of milk proteins from cloned and normal control goats displayed only one band for $\alpha$-lactalbumin, $\beta$-lactoglobulin, and $\alpha$-casein each, which indicated the lack of polymorphisms in these proteins. However, the $\beta$-casein of cloned goat C-50 produced two bands, suggesting the presence of protein polymorphisms.

\section{DISCUSSION}

Goat milk has important nutritional benefits in dietetics and therapeutics; an increase in the production of goat milk can therefore have a significant impact on the economy. The major goals of goat breeders are ensuring improved milk composition and yield. Milk production traits are under the control of several genes. Recent molecular biotechnological strategies offer rapid advances in breeding, such as trait selection and expression of desirable phenotypic characteristics. Therefore, the identification of molecular markers that correlate with selected characteristics of livestock production provides breeders with powerful tools for the genetic manipulation of breeding stock (Selvaggi et al., 2009; Dario and Selvaggi, 2011).

Proteins are the most important nutrients present in milk. The milk composition and protein content differ in different species, and are affected by many factors such as the lactation stage (Maria et al., 2014). The milk proteins in normal white goats and cloned goats were identified to be $\alpha$-lactalbumin, $\beta$-lactoglobulin, $\alpha$-casein, $\beta$-casein, and serum albumin; the protein constitution of goat milk was seen to be in agreement with those reported by previous studies in sheep and goats (Corral et al., 2010; Maria et al., 2014). In this study, two cloned goats with the same genetic background produced milk containing different proteins and different protein contents, despite being phenotypically (gender, coat color, and coat pattern) and genetically (DNA fingerprinting) identical; on the other hand, the phenotypically and genetically dissimilar three normal white goats (controls) produced milk with a similar protein composition and protein content. Milk samples were harvested from cloned goats on the first postpartum day. During this time point, goat clone C-50 had a higher casein content compared to goat clone $\mathrm{C}-4$, which had higher levels of $\beta$-casein (Figure 2 ). 
The milk proteins of goat clone C-4 were similar to those of the three normal white control goats, but differed from those of the genetically identical clone C-50. These results indicate that the milk composition and protein content is not identical in genetic clones. This result has not been reported in other studies on goat milk proteins, although genetically identical clones (or twins) can be biochemically and phenotypically different (Albert et al., 2005). Theoretically, this may be attributed to some non-chromosomal effects. Cloned goats C-50 and C-4 were derived from the same mammary epithelial cells. Paternity tests verified that they were derived from the same individual somatic chromosome. However, the cloned goat enucleated oocytes were prepared from different individuals. This suggested that milk protein composition and polymorphism could be determined by genetic, epigenetic, and/or cellular factors, and may depend on the complex interrelationships between these factors and the extracellular/environmental factors. We observed milk protein polymorphisms in different individuals during the different postpartum lactation stages, although the milk protein profiles and contents in the three normal white goats were essentially similar (Yuan et al., 2009). These results suggested that milk protein polymorphisms in cloned goats are due to genetic and cytoplasmic factors.

Modern advances in genetic and molecular methodologies enable the genetic analysis of milk protein polymorphisms, which aids in the identification and selection of favorable genotypes for high-yield milk production or milk with more desirable protein profiles. The direct relationship between allelic variants and milk protein content influences the physicochemical properties of milk, and may be utilized in breeding schemes to improve milk quality. Some authors have suggested that goat milk polymorphisms may influence milk allergenic effects; however, this theory must be extensively investigated. The high genetic diversity of goat milk protein genes suggests possibilities for further improvement of nutritional value. The traits of goat milk can be improved in the future by understanding the relationships between genetic polymorphisms and epigenetic or cellular changes.

\section{Conflicts of interest}

The authors declare no conflict of interest.

\section{ACKNOWLEDGMENTS}

Research financially supported by the National Major Special Projects on New Cultivation for Transgenic Organisms (\#2011ZX08008-004). The project was funded by the Priority Academic Program Development of Jiangsu Higher Education Institutions, Jiangsu Key Laboratory of Integrated Traditional Chinese and Western Medicine for Prevention and Treatment of Senile Diseases and The National Natural Science Foundation of China (\#31172284).

\section{REFERENCES}

Albert HCW, Irving IG and Arturas P (2005). Phenotypic differences in genetically identical organisms: the epigenetic perspective. Hum. Mol. Genet. 14: R11-R18.

Ambrosoli R, Di Stasio L and Mazzocco P (1988). Content of alpha S1-casein and coagulation properties in goat milk. J. Dairy Sci. 71: 24-28.

Amigo L, Recio I and Ramos M (2000). Genetic Polymorphism of ovine milk proteins: its influence on technological properties of milk-a review. Int. Dairy J. 10: 135-149.

Aschaffenburg R and Drewry J (1955). Occurrence of different $\beta$-lactoglobulin in cow's milk. Nature 176: 218-219.

Caravaca F, Carrizosa J, Urrutia B, Baena F, et al. (2009). Effect of aS1-casein (CSN1S1) and k-casein (CSN3) genotypes on milk composition in Murciano-Granadina goats. J. Dairy Sci. 92: 2960-2964. 
Corral JM, Padill JA and Izquierdo M (2010). Associations between milk protein genetic polymorphisms and milk production traits in Merino sheep breed. Livest. Sci. 129: 73-79.

Dario C and Selvaggi M (2011). Study on the STAT5A/Aval polymorphism in Jersey cows and association with milk production traits. Mol. Biol. Rep. 38: 5387-5392.

Ikonen T, Ojala M and Ruottinen O (1999). Associations between milk protein polymorphism and first lactation milk production traits in Finnish Ayrshire cows. J. Dairy Sci. 82: 1026-1033.

Laemmli UK (1970). Cleavage of structural proteins during assembly of the head of bacteriophage T4. Nature 277: 680-684.

Lagonigro R, Pietrosa E, D’Andrea M, Veltri C, et al. (2001). Molecular genetic characterization of the goat as2-caseine allele. Anim. Genet. 32: 391-393.

Lan XY, Pan CY, Chen H, Zhang CL, et al. (2007). An Mspl PCR-RFLP detecting a single nucleotide polymorphism at alphalactalbumin gene in goat. Czech J. Anim. Sci. 52: 138-142.

Luo J, Li JW and Liu Z (1994). The relationship of polymorphism of milk protein with dairy performance. Acta Univ. Agric. Boreali-occidentalis. 22: 12-16.

Marletta D, Bordonaro S, Guastella AM, Falagiani P, et al. (2004). Goat milk with different as2-casein content: analysis of allergenic potency by REAST inhibition assay. Small Rumin. Res. 52: 19-24

Medrano JF and Sharrow L (1989). Milk protein typing of bovine mammary gland tissue used to generate a complementary deoxyribonucleic acid library. J. Dairy Sci. 72: 3190-3196.

Pazzola M, Dettori ML, Pira E, Noce A, et al. (2014). Effect of polymorphisms at the casein gene cluster on milkrenneting properties of the Sarda goat. Small Rumin. Res. 117: 124-130.

Sacchi P, Chessa S, Budelli E, Bolla P, et al. (2005). Casein haplotype structure in five Italian goat breeds. J. Dairy Sci. 88: 1561-1568.

Selvaggi M, Dario C, Normanno G, Celano GV, et al. (2009). Genetic polymorphism of STAT5A protein: relationships with production traits and milk composition in Italian Brown cattle. J. Dairy Res. 76: 441-445.

Selvaggi M, Laudadio V, Dario C and Tufarelli V (2014). Major proteins in goat milk: an updated overview on genetic variability Mol. Biol. Rep. 41: 1035-1048.

Yuan YG, Cheng Y, Guo L, Ding GL, et al. (2009). Cloned kids derived from caprine mammary gland epithelial cells. Theriogenology, 72: 500-505.

Zulloa A, Baronea CMA, Chianeseb L, Colatruglioa P, et al. (2005). Protein polymorphisms and coagulation properties of cilentana goat milk. Small Rumin. Res. 58: 223-230. 